Special Section: Erosion and Lateral Surface Processes

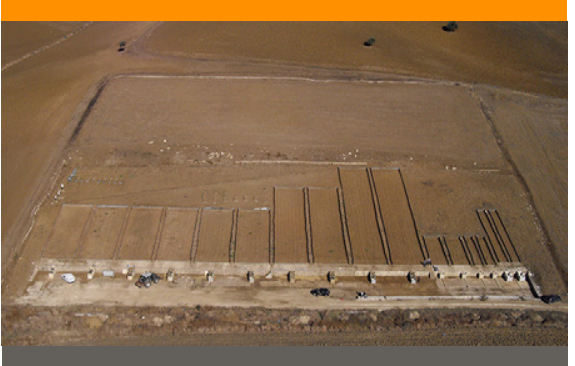

Core Ideas

- Explaining plot-scale effects

improves our understanding of

hydrological processes.

- Scale effects for sediment concen-

tration and runoff differed at the

Sparacia site.

- Establishing factors responsible

for scale effects needs additional

investigation.
V. Bagarello, Dip. Scienze Agrarie, Alimentari e Forestali, Univ. of Palermo, Viale delle Scienze, Palermo 90128, Italy; V. Ferro, Dip. di Scienze della Terra e del Mare, Univ. degli Studi di Palermo, Via Archirafi 22, Palermo 90123 Italy. *Corresponding author (vincenzo.bagarello@unipa.it).

Received 16 Mar. 2017. Accepted 1 Oct. 2017.

Citation: Bagarello, V., and V. Ferro. 2017. Scale effects on plot runoff and soil erosion in a Mediterranean environment. Vadose Zone J. 16(12). doi:10.2136/vzj2017.03.0059

Vol. 16, Iss. 12, 2017

(C) Soil Science Society of America 5585 Guilford Rd., Madison, WI 53711 USA. All rights reserved.

\section{Scale Effects on Plot Runoff and Soil Erosion in a Mediterranean Environment}

\section{Bagarello* and V. Ferro}

Explaining scale effects for runoff and erosion improves our understanding of hydrological and erosion processes. In this investigation, plot-scale effects on event runoff per unit area, $Q_{e^{\prime}}$ sediment concentration, $C_{e^{\prime}}$ and soil loss per unit area, $\mathrm{SL}_{e}$, were checked at the Sparacia (Italy) site. Similar information on the scale effects was obtained with different dependent variables, i.e., individual values of $Q_{e^{\prime}} C_{e^{\prime}}$ and $S_{e}$ for each plot or the mean of their replicated values, and scale indicators, i.e., plot length, I, or plot area, A. The most common result, occurring for 57 to $62 \%$ of the events depending on the considered variable, was the lack of any scale effect. When scale effects were detected, they indicated that longer plot lengths yielded smaller $Q_{e}$ and $\mathrm{SL}_{e}$ values and larger $\mathrm{C}_{e}$ values. Scale effects were more variable for erosion than runoff. Rainfall characteristics did not explain the occurrence of significant scale effects nor were they able to describe changes in the scaling exponent for $\mathrm{C}_{e}$ and $\mathrm{SL}_{e}$. However, there was some sign that scale effects for plot runoff decreased as rainfall amount or its erosivity increased. The collected data were not always sufficient to support the description of scale effects by the theoretically based power relationship. Additional investigations on plot-scale effects are advisable to both explain with more confidence what factors control the response of plots differing in length and establish the most appropriate way to summarize the data.

Investigating the scale dependency of plot runoff and soil erosion is important for different reasons. A fundamental reason is that explaining scale effects implies better understanding of the hydrological and erosion processes. For example, Chen et al. (2016) recently suggested that scale effects for Hortonian runoff were mostly due to run-on processes that increase infiltration with spatial heterogeneities in soil properties and runoff travel distances. They also showed that scale effects are smaller as rainfall intensity increases and they should become insignificant beyond a certain threshold scale. With reference to erosion, Loch (1996) suggested that three basic responses in erosion per unit area occur as slope length increases, i.e., little, moderate, and large increase determined by failure of rills to develop, slight rill development, and strong rill development, respectively. Parsons et al. (2006) suggested that sediment yield per unit area first increases as plot length increases but then subsequently decreases. Yair and Raz-Yassif (2004) reported positive relationships between slope length and deposition rates for an arid environment, and they suggested that the response of long hillslopes depends on both the concentration time required for continuous flow and the duration of the effective rain showers. According to Kidron (2011), contributing areas in arid zones can mainly be confined to a narrow belt at the bottom of the slope, and scale effects are an inherent outcome of rain properties due to the intermittent character of rain spells. Bagarello et al. (2011) noted that length effects on soil loss per unit area were small for highly erosive events. Of course, an improved understanding of the mechanisms responsible of the scale effects also has modeling implications. For example, Yair and Raz-Yassif (2004) also concluded that positive relationships between slope length and runoff and erosion rates should not be applied in arid to semiarid areas. Establishing scale dependency also has practical interest for a variety of reasons such as determining how agricultural field lengths influence areal water infiltration (Chen et al., 2016) or making decisions on the appropriate length of a plot to maintain soil erosion at tolerable levels (Di Stefano and Ferro, 2016) in a given environment. For this purpose, Bagarello and Ferro (2010) suggested that plot shortening 
represents an effective soil erosion control practice when rill erosion is the dominant subprocess.

The present approaches to establishing the existence of a contributing area imply some preliminary hypotheses that influence the obtained results. For example, Rejman et al. (1999) needed to assume that the smallest investigated plot contributed entirely to sediment yield, whereas Kidron (2011) assumed a constant and homogeneous expected infiltration rate across the entire plot. A challenge of this study was to see if the presence of a contributing area within the plot can be detected without any hypothesis simplifying the analysis.

Scale effects on soil hydrological and erosion variables have been tested under varying experimental conditions. A factor generally differing from one investigation to another is the range of the sampled slope lengths, for example, 10 to $60 \mathrm{~m}$ (Lal, 1997), 5 to $20 \mathrm{~m}$ (Rejman et al., 1999), 1 to $5 \mathrm{~m}$ (Chaplot and Le Bissonnais, 2000), 0.5 to $10 \mathrm{~m}$ (Joel et al., 2002), 2.5 to $20 \mathrm{~m}$ (Rejman and Usowicz, 2002; Rejman and Brodowski, 2005), 0.2 to $0.4 \mathrm{~m}$ (Bagarello and Ferro, 2004), 24 to $72 \mathrm{~m}$ (Yair and Raz-Yassif, 2004), 2 to $28 \mathrm{~m}$ (Parsons et al., 2006), 1 to $4 \mathrm{~m}$ (Xu et al., 2009), 0.25 to 44 and 11 to $44 \mathrm{~m}$ (Bagarello and Ferro, 2010), 1 to $15 \mathrm{~m}$ (Moreno-de las Heras et al., 2010), 11 to $22 \mathrm{~m}$ (Bagarello et al., 2011), 1 to $10 \mathrm{~m}$ (Thomaz and Vestena, 2012), and 2 to $25 \mathrm{~m}$ (Sadeghi et al., 2013). Within these ranges, two plot sizes (e.g., Chaplot and Le Bissonnais, 2000; Bagarello et al., 2011; Thomaz and Vestena, 2012) or more than two (e.g., Rejman et al., 1999; Parsons et al., 2006; Bagarello and Ferro, 2010) were sampled. Soil surface conditions also varied with the investigation. In particular, some plots were maintained bare during the experimental period (e.g., Bagarello and Ferro, 2010; Bagarello et al., 2011; Rejman et al., 1999). In other cases, plots differing in length had similar levels of vegetation cover (Moreno-de las Heras et al., 2010) or a mixture of desert pavement and vegetation cover (Parsons et al., 2006). Plots were cropped with different tillage methods during the experimental period in other investigations (Lal, 1997). Scale effects on both runoff and erosion were simultaneously tested in many investigations (Lal, 1997; Chaplot and Le Bissonnais, 2000; Parsons et al., 2006; Xu et al., 2009; Bagarello and Ferro, 2010; Moreno-de las Heras et al., 2010; Bagarello et al., 2011; Kidron 2011; Thomaz and Vestena, 2012) but only runoff (Joel et al., 2002; Yair and RazYassif, 2004) or erosion variables (Rejman et al., 1999; Rejman and Usowicz, 2002; Rejman and Brodowski, 2005) were considered in other cases.

The large variety of experimental conditions could be viewed as an obstacle to comparison of different investigations, but it also represents an opportunity to test hypotheses under different situations and hence to develop theories of large validity. Reaching this perhaps ambitious objective could be easier if some questions related to experimental testing of scale effects are answered. In particular, one of the still unsolved tasks is to establish if the chosen independent variable applied to check scale effects (plot length or area) affects the results of the analysis.

An obvious issue to be taken into account is the effect of the available experimental information on the reliability of a scale-effect analysis. For example, Kinnell (2008) questioned the analysis by Parsons et al. (2006) because a small number of events (10) was considered and data from some plots were missing. To explain his criticism, Kinnell (2008) reanalyzed the data of Parsons et al. (2006) by considering only the events for which data were recorded on all large plots. In this case, runoff and sediment yield per unit area decreased as plot length, $l$, increased, and $l$ had a nonsignificant effect on sediment concentration. Without wanting to get involved in the specific question (Parsons et al., 2008), the reasoning of Kinnell (2008) induces a belief that a data set for scale-effect analysis should be developed taking into account, at least, the following requirements: (i) sampling the largest possible number of erosive events; (ii) considering all soil erosion relevant variables, i.e., runoff, sediment concentration, and soil loss; and (iii) using data when plots of the prescribed sizes are simultaneously operating for an event. According to Chen et al. (2016), a power law relationship can be used to describe scale effects, with the exponent representing a measure of these effects. Therefore, an additional requirement for checking scale effects is including more than two plot sizes in the data set so that a reliable fitting of the scaling model to the data can be performed.

In any case, the scale analysis developed by Chen et al. (2016) is empirically based, as is common in this kind of investigation. The link between scaling relationships and the self-similarity concept (Barenblatt, 1979, 1987) suggests that a new theoretically based approach could be developed.

Another point needing consideration is establishing if, for plots having a regular shape (e.g., rectangular), scale effects should be established in terms of plot length or plot area, taking into account that plots can vary both in length and width. For example, the Sparacia (Sicily, Italy) database includes data collected on plots of $44 \mathrm{~m}^{2}$ and there are plots with this area of both 11 by $4 \mathrm{~m}$ and 22 by $2 \mathrm{~m}$ (e.g., Bagarello and Ferro, 2017). Clearly, a scale effect could be checked for these plots by reasoning in terms of plot length but not of plot area.

Approaches different from using a scaling relationship should be tested taking into account that the considered hydrological variables (runoff, sediment concentration, and soil loss) are characterized by a natural variability (Nearing, 1998). In other terms, each hydrological variable has a probability distribution that can be estimated for each plot size. These distributions could be effectively used to compare measurements of a given variable in plots of different size. In other words, the scale effects can be detected by comparing the sequence of historical events rather than values corresponding to a single event. 
The general objective of this investigation was to check scale effects on event runoff and soil erosion variables for the 11- to 44-m-long plots established at the Sparacia experimental area. The specific objectives were to: (i) establish a comparison among different scenarios, developed by describing the scale in terms of either plot length or plot area; (ii) determine the prevailing scale effects with reference to runoff, sediment concentration, and soil loss; and (iii) verify the relationships between scale effects and rainfall characteristics.

\section{Materials and Methods}

\section{Field Site and Data Collection}

The experimental station for soil erosion measurement, Sparacia, of the Agricultural, Food and Forest Sciences Department of Palermo University, is located in western Sicily, southern Italy, approximately $100 \mathrm{~km}$ south of Palermo. The soil has a clay texture (62\% clay, $33 \%$ silt, $5 \%$ sand). The study area and the experimental installation and procedures were described in more detail in other studies (Bagarello et al., 2008, 2010; Bagarello and Ferro, 2004, 2010), and they were omitted here for brevity reasons.

All data used in this investigation were collected on the 11- to 44-m-long plots established on a $14.9 \%$ sloped hillslope, having a width of $2 \mathrm{~m}$ (11- and 22-m-long plots), $4 \mathrm{~m}$ (11-m-long plots), or $8 \mathrm{~m}$ (22-, 33-, and 44-m-long plots). In particular, the number of replicated plots varied from two (11 by 2,11 by 4,22 by 2,33 by 8 , and 44 by $8 \mathrm{~m}$ ) to six ( 22 by $8 \mathrm{~m}$ ). Scale effects were tested at the event temporal scale with reference to total runoff, $Q_{\mathrm{e}}(\mathrm{mm})$, sediment concentration, $C_{\mathrm{e}}\left(\mathrm{kg} \mathrm{m}^{-3}\right)$, and soil loss per unit area, $\mathrm{SL}_{\mathrm{e}}\left(\mathrm{g} \mathrm{m}^{-2}\right)$. Individual plots yielding simultaneous measurements of these variables were considered to develop the database. An additional constraint to including an event in the database was the simultaneous functioning of at least one plot for each of the four lengths, with the aim to obtain reasonably homogeneous and comparable data. A total of 21 erosive events, occurring in the period September 2004 to March 2015, were selected according to these criteria, and $N=275 Q_{\mathrm{e}}, C_{\mathrm{e}}$, and $\mathrm{SL}_{\mathrm{e}}$ values were used in this investigation.

The restrictive criteria applied in this investigation to develop the database implied that another 14 events and 212 plot soil loss data collected in the same period were disregarded for different reasons, such as lack of runoff data or lack of data for a particular plot length. More in general, the data used in this investigation were extracted from a database including 56 erosive events sampled from January 2000 to March 2015. For these events, the mean rainfall depth and single-storm erosion index were $42.4 \mathrm{~mm}$ and $158.8 \mathrm{MJ} \mathrm{mm} \mathrm{ha}^{-1} \mathrm{~h}^{-1}$ (medians of $36.7 \mathrm{~mm}$ and 102.0 $\mathrm{MJ} \mathrm{mm} \mathrm{ha} \mathrm{ma}^{-1} \mathrm{~h}^{-1}$, respectively.

All considered plots were maintained in a bare condition during the sampling period. Hand implements were used for periodically tilling the upper soil layer, i.e., to remove weeds and after erosive events determining the development of rills.

Rainfall was generally measured for each event at a 1-min temporal resolution by a recording rain gauge located at the plot site, and both the rainfall depth, $P_{\mathrm{e}}(\mathrm{mm})$, and the single-storm erosion index, $\mathrm{EI}_{30}\left(\mathrm{MJ} \mathrm{mm} \mathrm{ha}{ }^{-1} \mathrm{~h}^{-1}\right.$ ) (Wischmeier and Smith, 1978), were determined. Additional information on the characteristics of the erosive event was gathered for a reduced data set (17 out of the 21 rainfall records). In particular, the following variables were extracted from each record: (i) mean rainfall intensity, $I_{\text {med }}$ $\left(\mathrm{mm} \mathrm{h}^{-1}\right)$, which was determined by considering only the $1-\mathrm{min}$ steps with rain; (ii) maximum rainfall intensity, $I_{\max }\left(\mathrm{mm} \mathrm{h}^{-1}\right)$, i.e., the intensity of the highest rainfall amount in a 1-min time period; (iii) the highest rainfall amount falling without interruption, $h_{\max }(\mathrm{mm})$; and (iv) the intensity of $h_{\max }, I_{h \max }\left(\mathrm{mm} \mathrm{h}^{-1}\right)$. Unfortunately, these data were not obtained for four events because the original hyetograph was lost due to a malfunctioning of the storage device (16 Nov. 2004) or rainfall data were collected, at least for a part of the event, at a 10-min temporal resolution because the events occurred during the maintenance period of the rain-gauge station and data from a nearby station, working at the longer time interval, were used in order to not lose all data for the event (18 and 28 Jan. and 17 Feb. 2015).

\section{Determining Scale Effects by Dimensional Analysis and Self-Similarity}

For checking the scale effects the following power law can be considered:

$\frac{y}{y_{\mathrm{r}}}=\left(\frac{l}{l_{\mathrm{r}}}\right)^{m}$

where $y$ is the dependent variable (runoff, sediment concentration, or soil loss) measured on the plot having a length $l, y_{\mathrm{r}}$ is the dependent variable measured on the reference plot having a length $l_{\mathrm{r}}$, and $m$ is the scaling exponent.

Equation [1] can be deduced using dimensional analysis and the self-similarity theory. In particular, using the event soil loss corresponding to a given plot length, $\mathrm{SL}_{\mathrm{e}}$, the scaling phenomenon can be represented by the following functional relationship:

$F\left(\mathrm{SL}_{\mathrm{e}}, l, \mathrm{SL}_{\mathrm{e}, \mathrm{r}}, l_{\mathrm{r}}, g, \rho_{\mathrm{s}}\right)=0$

where $\mathrm{SL}_{\mathrm{e}, \mathrm{r}}$ is the soil loss of the reference plot in the same event, $g$ is acceleration due to gravity, and $\rho_{s}$ is the sediment density.

The $\Pi$ Theorem or Riabucinski-Buckingham theorem of dimensional analysis states that the functional relationship representing a physical phenomenon that does not depend on the choice of the measurement units of the involved variables can be expressed in a dimensionless form (Barenblatt, 1987). In more detail, according 
to the $\Pi$ Theorem of dimensional analysis (Barenblatt, 1979, 1987), if a physical process can be mathematically represented by an equation relating $n$ dimensional variables that involve $k$ fundamental physical quantities, the same process can be represented by a functional relationship in which $n-k$ dimensionless groups $\Pi_{i}$ $(i=1, \ldots, n-k)$ of variables appear.

Applying the $\Pi$ Theorem, the functional relationship in Eq. [2] can be expressed by three dimensionless groups: $\Pi_{1}, \Pi_{2}, \Pi_{3}$ :

$\phi\left(\Pi_{1}, \Pi_{2}, \Pi_{3}\right)=0$

where $\phi$ is a functional symbol.

Using as fundamental physical quantities $l_{\mathrm{r}}, g$, and $\rho_{\mathrm{s}}$, the $\Pi_{1}$ dimensionless group has the following expression:

$\Pi_{1}=\mathrm{SL}_{\mathrm{e}} l_{\mathrm{r}}^{\alpha} g^{\beta} \rho_{\mathrm{s}}^{\gamma}$

where $\alpha, \beta$, and $\gamma$ are numeric constants. Substituting into Eq. [4] the measurement units of each variable, the following relationship is obtained:

$\Pi_{1}=\mathrm{kg} \mathrm{m}^{-2} \mathrm{~m}^{\alpha} \mathrm{m}^{\beta} \mathrm{s}^{-2 \beta} \mathrm{kg}^{\gamma} \mathrm{s}^{2 \gamma} \mathrm{m}^{-4 \gamma}$

Because the $\Pi_{1}$ group is dimensionless, the numerical values of the constants $\alpha, \beta$, and $\gamma$ are calculated by solving the following system of three equations:

$0=1+\gamma$

$0=-2+\alpha+\beta-4 \gamma$

$0=-2 \beta+2 \gamma$

The solution $\alpha=-1, \beta=-1$, and $\gamma=-1$ establishes that $\Pi_{1}$ is equal to the following ratio:

$\Pi_{1}=\frac{\mathrm{SL}_{\mathrm{e}}}{l_{\mathrm{r}} g \rho_{\mathrm{s}}}$

Using a similar procedure, the following expression of the dimensionless groups $\Pi_{2}$ and $\Pi_{3}$ can be obtained:

$$
\begin{aligned}
& \Pi_{2}=\frac{l}{l_{\mathrm{r}}} \\
& \Pi_{3}=\frac{S \mathrm{~L}_{\mathrm{e}, \mathrm{r}}}{l_{\mathrm{r}} g \rho_{\mathrm{s}}}
\end{aligned}
$$

Barenblatt (1987) suggested combining the original dimensionless groups to obtain new similarity parameters $\Pi$. The number of groups can be reduced because Barenblatt (1987, p. 104) established, "formulate the similarity law using as few similarity parameters as possible." According to this statement, using Eq. [7] and [9], the following dimensionless group is obtained:

$$
\Pi_{1,3}=\frac{\Pi_{1}}{\Pi_{3}}=\frac{S L_{\mathrm{e}}}{l_{\mathrm{r}} g \rho_{\mathrm{s}}} \frac{l_{\mathrm{r}} g \rho_{\mathrm{s}}}{S L_{\mathrm{e}, \mathrm{r}}}=\frac{\mathrm{SL}_{\mathrm{e}}}{S L_{\mathrm{e}, \mathrm{r}}}
$$

Taking into account that some groups were combined to deduce other dimensionless variables, the functional relationship Eq. [3] can be rewritten in the following explicit form:

$\Pi_{1,3}=f\left(\Pi_{2}\right)$

where $f$ is a functional symbol. Introducing into Eq. [11] each dimensionless group, the functional relationship can be rewritten in the following form:

$$
\frac{\mathrm{SL}_{\mathrm{e}}}{\mathrm{SL}_{\mathrm{e}, \mathrm{r}}}=f\left(\frac{l}{l_{\mathrm{r}}}\right)
$$

A physical phenomenon is defined as self-similar in a given dimensionless group $\Pi_{n}$ when the functional relationship $\Pi_{1}$ $=\phi\left(\Pi_{2}, \Pi_{3}, \ldots, \Pi_{n}\right)$ representing the physical phenomenon is independent of $\Pi_{n}$. The self-similar solutions of a problem must be found in accordance with the boundary conditions, that is, the behavior of the relationship $\phi$ must be solved for $\Pi_{n} \rightarrow 0$ and for $\Pi_{n} \rightarrow \infty$. When the relationship $\phi$ has a limit equal to 0 or $\infty$, the physical phenomenon is expressed by the following functional relationship:

$$
\Pi_{1}=\Pi_{n}^{\varepsilon} \phi_{1}\left(\Pi_{2}, \Pi_{3}, \ldots, \Pi_{n-1}\right)
$$

where $\varepsilon$ represents a numerical constant. This instance is named incomplete self-similarity (ISS) in the parameter $\Pi_{n}$ (Barenblatt, $1979,1987)$. Taking into account that when $l / l_{\mathrm{r}} \rightarrow 0$, then $\mathrm{SL}_{\mathrm{e}} /$ $\mathrm{SL}_{\mathrm{e}, \mathrm{r}} \rightarrow 0$ and when $l / l_{\mathrm{r}} \rightarrow+\infty$, then SL $\mathrm{e}_{\mathrm{e}} / \mathrm{SL}_{\mathrm{e}, \mathrm{r}} \rightarrow+\infty$, the ISS condition occurs for the dimensionless group $l / l_{r}$, and Eq. [12] has the following mathematical form:

$$
\frac{\mathrm{SL}_{\mathrm{e}}}{\mathrm{SL}_{\mathrm{e}, \mathrm{r}}}=a\left(\frac{l}{l_{\mathrm{r}}}\right)^{m}
$$

where $a$ and $m$ are coefficients to be determined by experimental measurements. The boundary condition corresponding to $l / l_{\mathrm{r}} \rightarrow$ $+\infty$ can be physically explained taking into account that when sediment delivery processes do not occur at the plot scale then the soil loss is always increasing with the plot length (Wischmeier and Smith, 1978). Then, taking into account that when $l=l_{\mathrm{r}}$ also SL $\mathrm{e}_{\mathrm{e}, A}$ $=\mathrm{SL}_{\mathrm{e}, \mathrm{r}}$, the $a$ coefficient of Eq. [14] is equal to 1 :

$$
\frac{\mathrm{SL}}{\mathrm{SL}}=\left(\frac{l}{l_{\mathrm{r}, \mathrm{r}}}\right)^{m}
$$


Equation [15] is also applicable to the mean value of the considered variable.

Chen et al. (2016) suggested to check scale effects at the event temporal scale using common regression analysis techniques to fit the following relationship to the data:

$y=b_{0} x^{b_{1}}$

where $y$ is the dependent variable (individual values or means of $Q_{\mathrm{e}}, C_{\mathrm{e}}$, or $\mathrm{SL}_{\mathrm{e}}$ for a given plot length or area, depending on the considered scenario), $x$ is the independent variable ( $l$ or $A$ ), and $b_{0}$ and $b_{1}$ are empirically derived coefficients. Equation [16] can be rewritten as

$$
\frac{y}{b_{0}}=\left(\frac{x}{1}\right)^{b_{1}}
$$

Therefore, the coefficient $b_{0}$ is the value of the selected variable for the reference plot, which is assumed to have an area of $1 \mathrm{~m}^{2}$ or a length of $1 \mathrm{~m}$. The power exponent, $b_{1}$, which is the scaling exponent, represents a measure of the scale effect on the considered variable. Equation [17] applied by Chen et al. (2016) is coincident with Eq. [15] deduced by dimensional analysis and self-similarity theory.

\section{Determining Scale Effects by Frequency Analysis of Soil Loss}

The proposed statistical check of scale effects aimed to establish if the probability distribution of the soil loss, $\mathrm{SL}_{\mathrm{e}}$, for a given plot length was able to reproduce the empirical frequency distribution of the measured soil loss values in plots having a different length. In particular, the check implied establishing if the probability distribution of $\mathrm{SL}_{\mathrm{e}}$ for the 44-m-long plots was overlaid on the frequency distribution of the measured soil loss values corresponding to $l=11 \mathrm{~m}$ and, conversely, if the probability distribution of $\mathrm{SL}_{\mathrm{e}}$ for the 11-m-long plots was able to reproduce the empirical frequency distribution of the measured soil loss values corresponding to $l=44 \mathrm{~m}$.

For a given plot length, the probability distribution of $\mathrm{SL}_{\mathrm{e}}$ (g $\mathrm{m}^{-2}$ ) was generated by multiplying the theoretical probability distribution of the concentration, $C_{\mathrm{e}}\left(\mathrm{kg} \mathrm{m}^{-3}\right)$, by the theoretical probability distribution of runoff, $Q_{\mathrm{e}}(\mathrm{mm})$. For obtaining the probability distribution of $\mathrm{SL}_{\mathrm{e}}$, repeated simulations were performed using randomly obtained values of the input variables $C_{\mathrm{e}}$ and $Q_{\mathrm{e}}$. In particular, for each simulation, the input values of $C_{\mathrm{e}}$ and $Q_{\mathrm{e}}$ were chosen using their known and predetermined probability distributions. The simulation process was repeated for a number of iterations sufficient to estimate the probability distribution of the output variable $\mathrm{SL}_{\mathrm{e}}$ to be compared with the empirical frequency distribution of the measured soil loss values.
At first, for a given plot length, the theoretical probability distribution that could be fitted to the empirical frequency distribution of both $C_{\mathrm{e}}$ and $Q_{\mathrm{e}}$ was established. A lognormal distribution with two parameters was fitted to the measured $C_{\mathrm{e}}$ and $Q_{\mathrm{e}}$ values. Then, each simulation was performed, drawing at random a concentration $C_{\mathrm{e}}$ and a runoff $Q_{\mathrm{e}}$ from their lognormal distributions to calculate the soil loss $\mathrm{SL}_{\mathrm{e}}$. Each subsequent simulation was repeated 20 times and a mean probability distribution function was obtained.

\section{Data Analysis}

Initially, the complete data set, including 21 erosive events, was considered for the analysis. For each considered variable $\left(Q_{\mathrm{e}}\right.$, $C_{\mathrm{e}}$, and $\mathrm{SL}_{\mathrm{e}}$ ), scale effects were checked at the event temporal scale by considering four different scenarios. In particular, both plot length, $l$, and area, $A$, were chosen as the independent variable because either of these two variables were used in previous investigations (Xu et al., 2009; Moreno-de las Heras et al., 2010; Cerdan et al., 2004; Asadzadeh et al., 2012; Chen et al., 2016). Both the individual data points, i.e., the data collected from each particular plot, and the means for a given treatment (i.e., individual data averaged by $l$ or $A$ ) were considered as the dependent variable. The individual data points were used to avoid giving the same weight to the different treatments (lengths or areas), which instead occurred when the means were considered. For example, even eight data points from the 22-m-long plots but no more than two data points from the 33- or 44-m-long plots were available for an event. With the use of the individual data, the difference in the available amount of information among the considered treatments was taken into account. On the other hand, it was also considered that plot data having the same treatment show a natural variability that is still not fully understood and may be considered random from a practical point of view (Wendt et al., 1986; Nearing, 2000; Bagarello and Ferro, 2004, 2010). Using the means was expected to offset heterogeneities, yielding a more representative information for a given treatment. In summary, the following scenarios were considered:

Scenario 1: individual values of the considered variable (a value for each plot operating at the time of the event) against plot length, $l$

Scenario 2: means of the considered variable for a given plot length against $l$

Scenario 3: individual values of the considered variable against plot area, $A$

Scenario 4: means of the considered variable for a given plot area against $A$

The statistical significance of the correlation (Eq. [16]) was checked by a one-tailed $t$-test at $P=0.05$ (Spiegel, 1961). A comparison among the four scenarios was then performed and the scenario yielding the highest number of detectable scale effects was considered in the subsequent stage of the investigation. 
For a given variable $\left(Q_{\mathrm{e}}, C_{\mathrm{e}}\right.$, or $\left.\mathrm{SL}_{\mathrm{e}}\right)$, two groups of events were obtained, depending on the statistical significance of the correlation coefficient, $R$ (events with a significant correlation and events with a nonsignificant correlation). A two-tailed $t$-test at $P=0.05$ was then used to compare rainfall depths and singlestorm erosion indices for these two groups of events in an attempt to establish if the existence or nonexistence of scale effects was related to the rainfall characteristics. For the events with a statistically significant scale effect, the correlation between $b_{1}$ and both $P_{\mathrm{e}}$ and $\mathrm{EI}_{30}$ was also checked. A seasonal influence on the scale effects was finally investigated by determining, for each month of the year, the number of events with significant and nonsignificant correlations.

With reference to the reduced data set, i.e., 17 erosive events, two groups of events were developed, depending on the statistical significance of $R$, and a two-tailed $t$-test $(P=0.05)$ was applied to compare $I_{\operatorname{med}}, I_{\max }, h_{\max }$, and $I_{b \max }$ for these two groups of events. For the events with a statistically significant scale effect, the correlation between $b_{1}$ and $I_{\text {med }}, I_{\text {max }}, h_{\text {max }}$, and $I_{b \max }$ was also checked.

Presentation of runoff and soil loss data as volume and mass per unit area, respectively, was questioned by some researchers because the contributing area can be expected to be confined to a narrow belt at the bottom of the slope (Kidron, 2011). However, this kind of presentation is consistent with most modeling procedures yielding, for example, soil loss per unit area (Wischmeier and Smith, 1978). Moreover, there is evidence that this way to proceed is appropriate to improve our physical understanding of scale effects (e.g., Parsons et al., 2006; Chen et al., 2016). Finally, it is still necessary to establish potentials and limitations of the suggested alternative ways to present the data, such as quantities per unit width of the slope (Kidron, 2011).

\section{Results}

\section{General Characteristics of the Data Set}

With reference to the 21 sampled events, both $P_{\mathrm{e}}$ and $\mathrm{EI}_{30}$ varied by approximately one order of magnitude (maximum/minimum $=9.9$ and 11.6, respectively, Table 1) but $Q_{\mathrm{e}}, C_{\mathrm{e}}$, and $\mathrm{SL}_{\mathrm{e}}$ varied by more than three $\left(Q_{\mathrm{e}}\right.$, maximum $/$ minimum $\left.=1535\right)$ or four $\left(C_{\mathrm{e}}\right.$, maximum $/ \mathrm{minimum}=17,881 ; \mathrm{SL}_{\mathrm{e}}$, maximum $/$ minimum $=23,757)$ orders of magnitude. These wide ranges of variation suggested a satisfactory representativeness of the considered data set for the Sparacia site. Variability of the plot response in terms of both runoff and soil erosion variables was much higher than variability of the rainfall determining that response. Regardless of plot length, soil erosion variables varied more than runoff amount (Table 1), indicating a greater complexity of the soil particle detachment and transport process than the runoff process (Bagarello et al., 2010).
Table 1. Summary statistics of the event rainfall depth, $P_{\mathrm{e}}$, single-storm erosion index, $\mathrm{EI}_{30}$, runoff, $Q_{\mathrm{e}}$, sediment concentration, $C_{\mathrm{e}}$, and soil loss per unit area, $\mathrm{SL}_{\mathrm{e}}$, used in the investigation.

\begin{tabular}{|c|c|c|c|c|c|}
\hline \multirow[b]{2}{*}{ Variable } & \multirow[b]{2}{*}{ Statistic } & \multicolumn{4}{|c|}{ Plot length (m) } \\
\hline & & 11 & 22 & 33 & 44 \\
\hline \multirow[t]{6}{*}{$P_{\mathrm{e}}, \mathrm{mm}$} & $N$ & \multicolumn{4}{|c|}{21} \\
\hline & $\min$. & \multicolumn{4}{|c|}{14.8} \\
\hline & $\max$ & \multicolumn{4}{|c|}{145.8} \\
\hline & mean & \multicolumn{4}{|c|}{48.4} \\
\hline & median & \multicolumn{4}{|c|}{43.0} \\
\hline & $\mathrm{CV}, \%$ & \multicolumn{4}{|c|}{61.4} \\
\hline \multirow[t]{6}{*}{$\mathrm{EI}_{30}, \mathrm{MJ} \mathrm{mm} \mathrm{ha} \mathrm{h}^{-1} \mathrm{~h}^{-1}$} & $N$ & \multicolumn{4}{|c|}{21} \\
\hline & $\min$. & \multicolumn{4}{|c|}{29.5} \\
\hline & $\max$ & \multicolumn{4}{|c|}{341.6} \\
\hline & mean & \multicolumn{4}{|c|}{144.3} \\
\hline & median & \multicolumn{4}{|c|}{111.3} \\
\hline & $\mathrm{CV}, \%$ & \multicolumn{4}{|c|}{66.7} \\
\hline \multirow[t]{6}{*}{$Q_{e}, \mathrm{~mm}$} & $N$ & 73 & 120 & 42 & 40 \\
\hline & $\min$. & 0.07 & 0.06 & 0.03 & 0.14 \\
\hline & $\max$ & 41.63 & 40.16 & 9.54 & 6.88 \\
\hline & mean & 8.47 & 6.33 & 4.66 & 2.42 \\
\hline & median & 3.05 & 5.29 & 4.02 & 1.51 \\
\hline & $\mathrm{CV}, \%$ & 127.6 & 93.2 & 81.8 & 98.0 \\
\hline \multirow[t]{6}{*}{$C_{\mathrm{e}}, \mathrm{kg} \mathrm{m}^{-3}$} & $N$ & 73 & 120 & 42 & 40 \\
\hline & $\min$. & 0.20 & 0.34 & 1.82 & 0.33 \\
\hline & $\max$ & 1063.97 & 472.32 & 1028.30 & 3546.11 \\
\hline & mean & 79.03 & 69.31 & 123.28 & 208.20 \\
\hline & median & 17.80 & 26.53 & 33.84 & 20.42 \\
\hline & $\mathrm{CV}, \%$ & 208.8 & 150.2 & 172.7 & 283.8 \\
\hline \multirow[t]{6}{*}{$\mathrm{SL}_{\mathrm{e}}, \mathrm{g} \mathrm{m}^{-2}$} & $N$ & 73 & 120 & 42 & 40 \\
\hline & $\min$. & 0.48 & 0.74 & 1.16 & 0.16 \\
\hline & $\max$ & 3805.38 & 2546.54 & 3533.13 & 1974.23 \\
\hline & mean & 349.12 & 291.57 & 419.73 & 264.78 \\
\hline & median & 141.94 & 94.25 & 67.94 & 31.43 \\
\hline & $\mathrm{CV}, \%$ & 185.0 & 168.3 & 178.4 & 160.3 \\
\hline
\end{tabular}

\section{Testing Scale Effects by Plot Length and Area}

Visual examination of the individual $Q_{\mathrm{e}}, C_{\mathrm{e}}$, and $\mathrm{SL}_{\mathrm{e}}$ values against both $l$ (Fig. 1a, 1b, and 1c) and $A$ (Fig. 1d, 1e, and 1f) (sample size $N=275$ for each graph in the figure) suggested a scale effect with reference to $Q_{\mathrm{e}}$ because this variable appeared to decrease as plot size $(l$ or $A)$ increased. A weak increasing trend with both $l$ and $A$ was detected for $C_{\mathrm{e}}$, and an independence of $\mathrm{SL}_{\mathrm{e}}$ from plot size $(l$ or $A)$ was also noticed. Reasoning in terms of means, $Q_{\mathrm{e}}$ decreased as $l$ and $A$ increased, $C_{\mathrm{e}}$ showed a non-monotonic increase with the two scale indicators, and $\mathrm{SL}_{\mathrm{e}}$ appeared to be practically independent of both $l$ and $A$. With the medians, both $Q_{\mathrm{e}}$ and $C_{\mathrm{e}}$ first increased and then decreased, while $\mathrm{SL}_{\mathrm{e}}$ decreased as $l$ and $A$ increased. Therefore, this initial check of the collected data suggested a similarity between $l$ and $A$ as scale indicators. Longer 

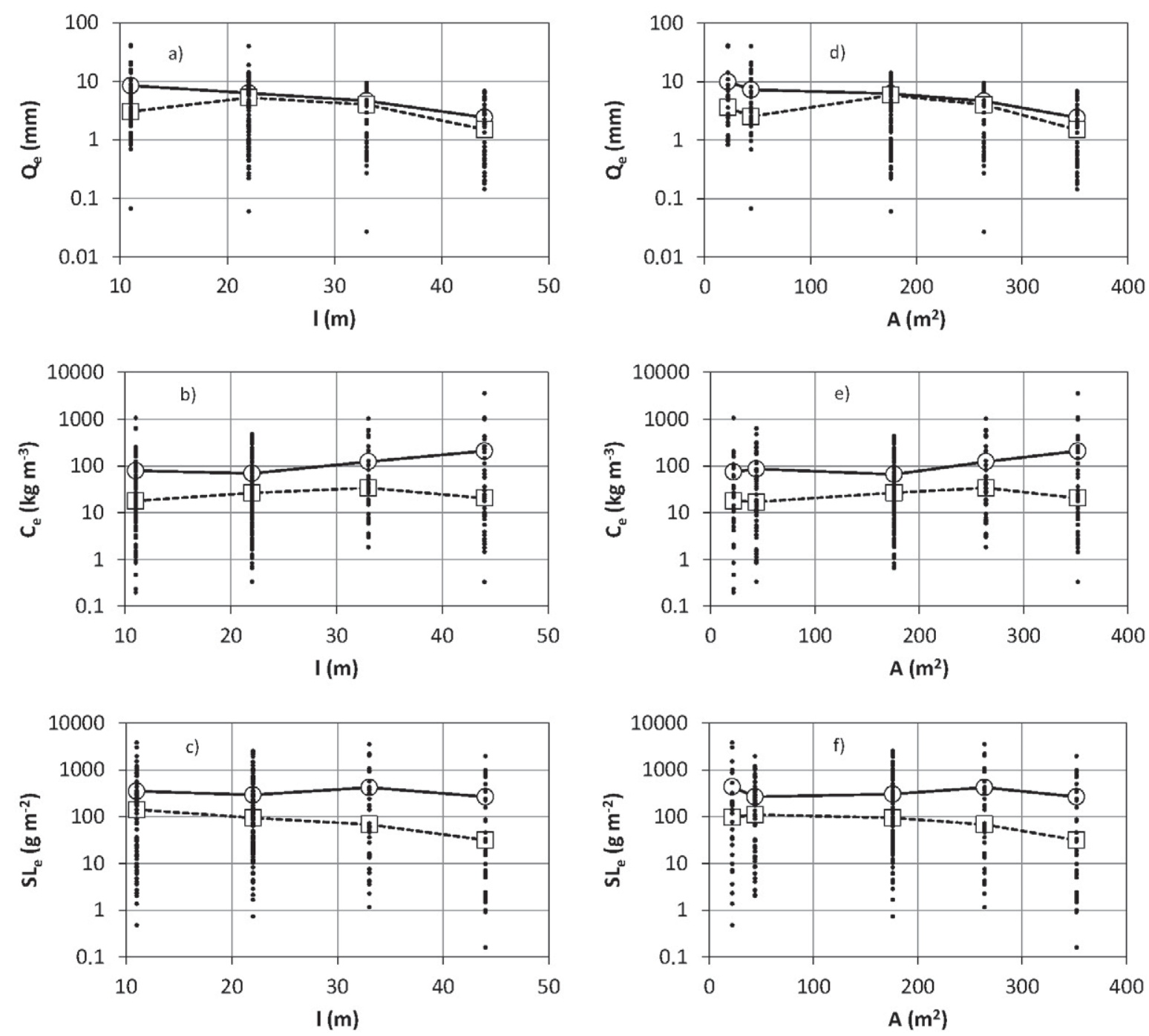

Fig. 1. Plot of the event runoff, $Q_{\mathrm{e}}$, sediment concentration, $C_{\mathrm{e}}$, and soil loss per unit area, $\mathrm{SL}_{\mathrm{e}}$, against the plot length, $l$, and area, $A$ (sample size, $N=275$ data pairs in each graph). White circles are mean values; white squares are median values).

or larger plots yielded more or less clearly a decreasing runoff per unit area, an increasing or nearly constant sediment concentration, and a constant or decreasing soil loss per unit area, depending on the statistic (mean or median) used to summarize the data.

Regardless of the considered scenario (1-4), a negative $b_{1}$ value of Eq. [16] was the most frequent result for both $Q_{\mathrm{e}}(90-95 \%$ of the cases, depending on the scenario) and, to a lesser degree, $\mathrm{SL}_{\mathrm{e}}(57-71 \%$ of the cases) (Table 2). On the contrary, a positive $b_{1}$ value was most common with reference to $C_{\mathrm{e}}(71-81 \%$ of the cases). However, $R>$ 0 was detected for a minor part of the sampled events, regardless of the considered variables and scenarios (19-43\%). With reference to the statistically significant relationships, $b_{1}$ was always negative for $Q_{\mathrm{e}}$ and most often negative (50-75\% of the cases) for $\mathrm{SL}_{\mathrm{e}}$. With reference to $C_{\mathrm{e}}$, a positive $b_{1}$ exponent was obtained in most cases $(80-89 \%)$. Therefore, the four different scenarios consistently indicated that the lack of any scale effect was the most common result with reference to the three tested variables. When a significant scale effect was detected, the indication was that runoff always decreased, sediment concentration generally increased, and soil loss per unit area most frequently decreased in longer or larger plots.

The similarity of the information obtained with different scenarios was an encouraging result because it implies that investigations performed with different approaches (individual plot values or means of replicate determinations, plot length or area as a scale indicator) should yield comparable information from a qualitative point of view. However, the suggested similarity did not imply a perfect equivalence of the four scenarios. In particular, with reference to both $C_{\mathrm{e}}$ and $\mathrm{SL}_{\mathrm{e}}$, significant scale effects were more frequently detected when the individual values of the considered variable were used (Scenarios 1 and 3) instead of the means (Scenarios 2 and 4) (Table 2). The opposite result was obtained for $Q_{\mathrm{e}}$.

With reference to the events with a significant scale effect for both the first (individual values vs. $l$ ) and the third (individual values vs. 
Table 2. Summary of the scale effects for event runoff $\left(Q_{\mathrm{e}}\right)$, sediment concentration $\left(C_{\mathrm{e}}\right)$, and soil loss per unit area $\left(\mathrm{SL}_{\mathrm{e}}\right)$ : number of positive and negative exponents, $b_{1}$, of Eq. [16], number of statistically significant and nonsignificant correlations, and number of positive and negative $b_{1}$ values for the statistically significant correlations ( $N=21$ erosive events).

\begin{tabular}{|c|c|c|c|c|c|c|c|}
\hline \multirow[b]{2}{*}{ Variable } & \multirow[b]{2}{*}{ Scenario $\dagger$} & \multicolumn{2}{|l|}{$b_{1}$} & \multicolumn{2}{|l|}{$R$} & \multicolumn{2}{|c|}{$b_{1}$ for $R>0$} \\
\hline & & Positive & Negative & $>0$ & $=0$ & Positive & Negative \\
\hline \multirow[t]{4}{*}{$Q_{\mathrm{e}}$} & 1 & 2 & 19 & 8 & 13 & 0 & 8 \\
\hline & 2 & 1 & 20 & 9 & 12 & 0 & 9 \\
\hline & 3 & 2 & 19 & 6 & 15 & 0 & 6 \\
\hline & 4 & 1 & 20 & 8 & 13 & 0 & 8 \\
\hline \multirow[t]{4}{*}{$C_{\mathrm{e}}$} & 1 & 17 & 4 & 9 & 12 & 8 & 1 \\
\hline & 2 & 16 & 5 & 5 & 16 & 4 & 1 \\
\hline & 3 & 15 & 6 & 8 & 13 & 7 & 1 \\
\hline & 4 & 17 & 4 & 7 & 14 & 6 & 1 \\
\hline \multirow[t]{4}{*}{$\mathrm{SL}_{\mathrm{e}}$} & 1 & 6 & 15 & 8 & 13 & 2 & 6 \\
\hline & 2 & 7 & 14 & 5 & 16 & 2 & 3 \\
\hline & 3 & 7 & 14 & 9 & 12 & 4 & 5 \\
\hline & 4 & 9 & 12 & 4 & 17 & 2 & 2 \\
\hline
\end{tabular}

† Scenario 1: individual values of the considered variable (a value for each plot operating at the time of the event) against plot length, $l$; Scenario 2 : means of the considered variable for a given plot length against $l$; Scenario 3: individual values of the considered variable (a value for each plot operating at the time of the event) against plot area, $A$; Scenario 4 : means of the considered variable for a given plot area against $A$.

A) scenario, the relationship between the two scaling exponents for an event was independent of the considered variable (Fig. 2), and the ratio between the two scaling exponents for an event $\left(b_{1}\right.$ for Scenario $1 / b_{1}$ for Scenario 3) had a low variability (coefficient of variation, CV $=13.1 \%$ ) around the mean value of 1.93 . This last result supported the assumption by $\mathrm{Chen}$ et al. (2016) of $A \sim R$ to compare investigations using either $l$ or $A$ to check scale effects. In addition, using the Chen et al. (2016) assumption, Eq. [15] can be rewritten as

$\frac{\mathrm{SL}_{\mathrm{e}}}{\mathrm{SL}_{\mathrm{e}, \mathrm{r}}}=\left(\frac{l^{2}}{l_{\mathrm{r}}^{2}}\right)^{m / 2}=\left(\frac{A}{A_{\mathrm{r}}}\right)^{m / 2}$

Equation [18] states that the scaling exponent for the area is half of the scaling exponent for length. Moreover, the data also indicated that the relationship between the two estimates of $b_{1}$ was independent of the considered hydrological or erosion variable.

The overall largest number of scale effects was detected with reference to Scenario 1, i.e., individual values of the considered variable against plot length (25 cases, Table 2$)$, compared with the other scenarios ( $\leq 23$ cases), and therefore the former scenario was considered in the subsequent analysis.

\section{Plot Length Effects on Individual Values of Hydrological and Erosion Variables}

Detection of scale effects for a given event was generally (i.e., in the $62 \%$ of the cases) variable dependent, in the sense that these

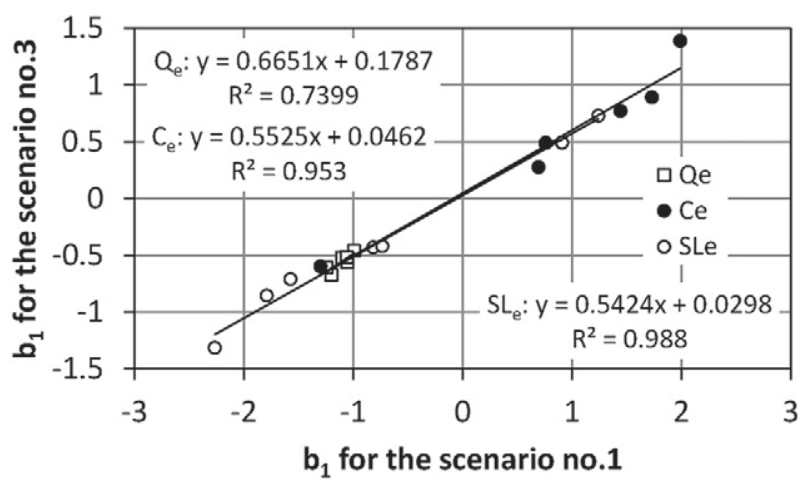

Fig. 2. Relationship between the scaling exponent $b_{1}$ for Scenarios 1 (individual values of the considered variable against plot length) and 3 (individual values of the considered variable against plot area) for the variables event runoff, $Q_{\mathrm{e}}$, sediment concentration, $C_{\mathrm{e}}$, and soil loss per unit area, $\mathrm{SL}_{\mathrm{e}}$.

effects were noticed for one or two variables but not for the other one or two variables (Table 3 ). The lack of any statistically significant relationship with $l$ was the most common result for all considered variables ( $57 \%$ of the cases for $C_{\mathrm{e}}$ and $62 \%$ for both $Q_{e}$ and $\mathrm{SL}_{\mathrm{e}}$, Table 3). In the other cases, runoff always decreased as plot length increased $\left(b_{1}\right.$ of Eq. [16] ranging with the event from -1.24 to -0.49 , Table 4 ). For $C_{\mathrm{e}}$, an inverse relationship was detected only once $\left(b_{1}=-1.30\right)$, whereas an increasing relationship, with $b_{1}$ values varying with the event from 0.32 to 1.99 , was most common (89\% of the significant relationships). With reference to $\mathrm{SL}_{\mathrm{e}}$, an increasing relationship was detected twice $\left(b_{1}=0.91-1.24\right)$ but a decreasing relationship, with $b_{1}$ values varying with the event from -2.26 to -0.68 , was most common ( $75 \%$ of the significant relationships). Therefore, the general tendency was to not detect significant scale effects at the sampled field site. When these effects were detectable, they implied a clear decreasing trend with $l$ for $Q_{e}$ and a less clear trend (i.e., with a few exceptions) for both $C_{\mathrm{e}}$, generally increasing, and $\mathrm{SL}_{\mathrm{e}}$, generally decreasing.

The most frequent condition determining the lack of any statistically significant relationship between $\mathrm{SL}_{\mathrm{e}}$ and $l$ ( $46 \%$ of the cases) was that both $Q_{\mathrm{e}}$ and $C_{\mathrm{e}} \operatorname{did}$ not depend on $l$ (Table 3). The most frequent condition determining an inverse relationship between $\mathrm{SL}_{\mathrm{e}}$ and $l$ (50\% of the cases) was that $Q_{\mathrm{e}}$ decreased with $l$ and $C_{\mathrm{e}}$ did not change with the plot length. However, statistically nonsignificant relationships between $\mathrm{SL}_{\mathrm{e}}$ and $l$ were also detected when longer plots yielded less runoff but a similar sediment concentration compared with shorter plots (events of 18 and 28 Jan. 2015), and inverse relationships between $\mathrm{SL}_{\mathrm{e}}$ and $l$ were detected even if both $Q_{\mathrm{e}}$ and $C_{\mathrm{e}}$ were unaffected by plot length (event of 3 Sept. 2013). Moreover, qualitatively similar scale effects with reference to runoff and sediment concentration, such as a decreasing $Q_{\mathrm{e}}$ and an increasing $C_{\mathrm{e}}$, determined all possible results in terms of soil loss, such as increasing (10 Dec. 2005), unvarying (9 Feb. 2010), and decreasing (16 Dec. 2004). 
Table 3. Coefficients of determination, $R^{2}$, of the tested relationships between the hydrological and sedimentological variables (event runoff $Q_{\mathrm{e}}$, sediment concentration $C_{\mathrm{e}}$, and soil loss per unit area $\mathrm{SL}_{\mathrm{e}}$ ) measured on each individual plot and plot length, l (i.e., Scenario 1), and values of the $b_{1}$ exponent of Eq. [16] for the statistically significant correlations.

\begin{tabular}{|c|c|c|c|c|c|c|c|}
\hline \multirow[b]{2}{*}{ Event } & \multirow{2}{*}{$\begin{array}{l}\text { Sample } \\
\text { size }\end{array}$} & \multicolumn{2}{|l|}{$Q_{\mathrm{e}}$} & \multicolumn{2}{|l|}{$C_{\mathrm{e}}$} & \multicolumn{2}{|l|}{$\mathrm{SL}_{\mathrm{e}}$} \\
\hline & & $b_{1}$ & $R^{2}$ & $b_{1}$ & $R^{2}$ & $b_{1}$ & $R^{2}$ \\
\hline 16 Sept. 2004 & 13 & $-\dagger$ & 0.091 & -1.297 & 0.733 & -1.788 & 0.620 \\
\hline 13 Oct. 2004 & 13 & -1.097 & 0.841 & - & 0.224 & -1.572 & 0.600 \\
\hline 2 Nov. 2004 & 12 & -1.198 & 0.778 & - & 0.140 & -0.816 & 0.280 \\
\hline 16 Nov.2004 & 13 & - & 0.192 & - & 0.029 & - & 0.038 \\
\hline 9 Dec. 2004 & 13 & - & 0.106 & 0.323 & 0.252 & - & 0.006 \\
\hline 16 Dec. 2004 & 13 & -1.053 & 0.875 & 0.320 & 0.239 & -0.733 & 0.501 \\
\hline 28 Feb. 2005 & 11 & - & 0.096 & - & 0.083 & - & 0.035 \\
\hline 11 Apr. 2005 & 12 & - & 0.101 & - & 0.040 & - & 0.010 \\
\hline 10 Dec. 2005 & 9 & -0.489 & 0.479 & 1.733 & 0.615 & 1.243 & 0.386 \\
\hline 25 Feb. 2006 & 12 & - & 0.001 & 0.691 & 0.298 & - & 0.180 \\
\hline 25 Sept. 2007 & 16 & -0.990 & 0.647 & - & 0.118 & -0.677 & 0.324 \\
\hline 18 Oct. 2008 & 12 & - & 0.074 & 0.695 & 0.635 & - & 0.103 \\
\hline 28 Oct. 2008 & 14 & - & 0.173 & 1.444 & 0.461 & 0.911 & 0.214 \\
\hline 28 Nov. 2008 & 14 & - & 0.034 & - & 0.009 & - & 0.022 \\
\hline 13 Jan. 2010 & 16 & - & 0.139 & - & 0.001 & - & 0.046 \\
\hline 9 Feb. 2010 & 16 & -1.057 & 0.598 & 0.760 & 0.186 & - & 0.025 \\
\hline 3 Sept. 2013 & 12 & - & 0.142 & - & 0.137 & -2.263 & 0.466 \\
\hline 18 Jan. 2015 & 13 & -1.244 & 0.740 & - & 0.096 & - & 0.079 \\
\hline 28 Jan. 2015 & 13 & -1.105 & 0.247 & - & 0.025 & - & 0.019 \\
\hline 17 Feb. 2015 & 16 & - & 0.180 & 1.991 & 0.208 & - & 0.121 \\
\hline 16 Mar. 2015 & 12 & - & $3 \times 10^{-6}$ & - & 0.031 & - & 0.020 \\
\hline
\end{tabular}

† Statistically nonsignificant relationship.

Statistically significant scale effects with reference to all tested variables, i.e., $Q_{\mathrm{e}}, C_{\mathrm{e}}$, and $\mathrm{SL}_{\mathrm{e}}$, were only detected for two events (16 Dec. 2004 and 10 Dec. 2005, Table 3). In both cases, the experimental $b_{1}$ value for $\mathrm{SL}_{\mathrm{e}}(-0.73$ and 1.24 , respectively) was equal to the algebraic sum of the $b_{1}$ values for $Q_{e}$ and $C_{\mathrm{e}}$. This was an expected result because $A_{\mathrm{e}}$ is given by the product between these last two variables, and it suggested that scale effects on soil loss per unit area are a combination of scale effects on both runoff and sediment concentration.

Regardless of the considered variable $\left(Q_{\mathrm{e}}, C_{\mathrm{e}}\right.$, or $\left.\mathrm{SL}_{\mathrm{e}}\right)$, events with significant and nonsignificant scale effects had similar rainfall depths, $P_{\mathrm{e}}$, and single storm erosion indices, $\mathrm{EI}_{30}$ (Table 4). In other words, the two types of response were not explained by differences in $P_{\mathrm{e}}$ or $\mathrm{EI}_{30}$.

With reference to the events suggesting the occurrence of significant scale effects, similar mean and median values of $b_{1}$ were obtained for each hydrological and erosion variable (Table 4). On average, both runoff and soil loss per unit area decreased as $l$ increased, whereas sediment concentration increased with $l$. In
Table 4. Summary statistics of the $b_{1}$ exponent of Eq. [16] for the events suggesting a significant correlation between the hydrological variable (event runoff $Q_{e}$, sediment concentration $C_{\mathrm{e}}$, and soil loss per unit area $\mathrm{SL}_{\mathrm{e}}$ ) measured on each individual plot and plot length (i.e., Scenario 1), comparison between the event rainfall amount $\left(P_{\mathrm{e}}\right)$ and the singlestorm erosion index $\left(\mathrm{EI}_{30}\right)$ for the two groups of events (events with a significant correlation and events with a nonsignificant correlation), and results of the linear regression analysis between $b_{1}$ and both $P_{\mathrm{e}}$ and $\mathrm{EI}_{30}$ for those events suggesting the existence of a statistically significant scale effect (total sample size $N=21$ events)

\begin{tabular}{|c|c|c|c|c|c|}
\hline $\begin{array}{l}\text { Variable or tested } \\
\text { relationship }\end{array}$ & Note & Statistic & $Q_{\mathrm{e}}$ & $C_{\mathrm{e}}$ & $\mathrm{SL}_{\mathrm{e}}$ \\
\hline \multirow[t]{5}{*}{$b_{1}$} & \multirow{5}{*}{$\begin{array}{r}\text { events with a } \\
\text { significant } \\
\text { correlation }\end{array}$} & min. & -1.24 & -1.30 & -2.26 \\
\hline & & $\max$. & -0.49 & 1.99 & 1.24 \\
\hline & & mean & -1.03 & 0.74 & -0.71 \\
\hline & & median & -1.08 & 0.70 & -0.78 \\
\hline & & $\mathrm{CV}, \%$ & 22.6 & 131.3 & 174.3 \\
\hline \multirow[t]{8}{*}{$P_{\mathrm{e}}, \mathrm{mm}$} & \multirow{4}{*}{$\begin{array}{r}\text { events with a } \\
\text { significant } \\
\text { correlation }\end{array}$} & $\min$. & 27.0 & 14.8 & 14.8 \\
\hline & & $\max$ & 97.8 & 145.8 & 97.8 \\
\hline & & mean & 55.9a† & $56.8 \mathrm{a}$ & $45.6 a$ \\
\hline & & median & 39.9 & 76.7 & 62.4 \\
\hline & \multirow{4}{*}{$\begin{array}{l}\text { events with a } \\
\text { nonsignificant } \\
\text { correlation }\end{array}$} & min. & 14.8 & 24.2 & 15.8 \\
\hline & & $\max$. & 145.8 & 57.0 & 145.8 \\
\hline & & mean & $43.8 \mathrm{a}$ & $42.1 \mathrm{a}$ & $50.1 \mathrm{a}$ \\
\hline & & median & 76.4 & 26.4 & 62.8 \\
\hline \multirow[t]{3}{*}{$b_{1}$ vs. $P_{\mathrm{e}}$} & \multirow{3}{*}{$\begin{array}{l}\text { events with a } \\
\text { significant } \\
\text { correlation }\end{array}$} & intercept & -1.4717 & - & - \\
\hline & & slope & 0.0079 & - & - \\
\hline & & $R^{2}$ & $0.5759^{*}$ & $\begin{array}{l}0.2666 \\
\mathrm{~ns}\end{array}$ & $\begin{array}{l}0.2127 \\
\mathrm{~ns}\end{array}$ \\
\hline \multirow{8}{*}{$\begin{array}{l}\mathrm{EI}_{30}, \\
\quad \mathrm{MJ} \mathrm{mm} \mathrm{ha}{ }^{-1} \mathrm{~h}^{-1}\end{array}$} & \multirow{4}{*}{$\begin{array}{r}\text { events with a } \\
\text { significant } \\
\text { correlation }\end{array}$} & $\min$. & 51.2 & 57.9 & 57.9 \\
\hline & & $\max$ & 334.0 & 334.0 & 334.0 \\
\hline & & mean & $158.7 \mathrm{a}$ & $152.3 \mathrm{a}$ & $182.2 \mathrm{a}$ \\
\hline & & median & 69.8 & 63.4 & 53.3 \\
\hline & \multirow{4}{*}{$\begin{array}{l}\text { events with a } \\
\text { nonsignificant } \\
\text { correlation }\end{array}$} & min. & 29.5 & 29.5 & 29.5 \\
\hline & & $\max$. & 341.6 & 341.6 & 341.6 \\
\hline & & mean & $135.3 \mathrm{a}$ & $138.2 \mathrm{a}$ & $120.9 a$ \\
\hline & & median & 66.2 & 72.1 & 75.6 \\
\hline \multirow[t]{3}{*}{$b_{1}$ vs. $\mathrm{EI}_{30}$} & \multirow{3}{*}{$\begin{array}{r}\text { events with a } \\
\text { significant } \\
\text { correlation }\end{array}$} & intercept & -1.2474 & - & - \\
\hline & & slope & 0.0014 & - & - \\
\hline & & $R^{2}$ & $0.4280^{*}$ & $\begin{array}{c}0.1180 \\
\mathrm{~ns}\end{array}$ & $\begin{array}{c}0.0006 \\
\text { ns }\end{array}$ \\
\hline
\end{tabular}

* Coefficient of correlation significantly $>0$ according to a one-tailed $t$-test $(P=$ $0.05)$; ns, coefficient of correlation not significantly $>0$.

† For a given variable $\left(Q_{\mathrm{e}}, C_{\mathrm{e}}, \mathrm{SL}_{\mathrm{e}}\right)$, the mean values of a rainfall characteristic $\left(P_{\mathrm{e}}\right.$ or $\left.\mathrm{EI}_{30}\right)$ followed by the same lowercase letter are not significantly different according to a two-tailed $t$-test $(P=0.05)$.

particular, the mean values of $b_{1}$ suggested that an increase in length from 11 to $44 \mathrm{~m}$ determined a reduction in runoff and soil loss per unit area by factors of 4.2 and 2.7 , respectively, and an increase in sediment concentration by a factor of 2.8 . In other terms, the decrease in soil loss was smaller than the decrease in runoff due to the partially compensating effect attributable to sediment concentration. Variability of $b_{1}$ was low with reference to $Q_{\mathrm{e}}$ 
$(\mathrm{CV}=23 \%)$ and high for both $C_{\mathrm{e}}$ and $\mathrm{SL}_{\mathrm{e}}(\mathrm{CV}=131$ and $174 \%$, respectively). Therefore, scale effects on both sediment concentration and soil loss were highly variable, i.e., they varied greatly from event to event. Instead, scale effects on runoff were comparatively much more stable, i.e., less event dependent.

Rainfall characteristics $\left(P_{\mathrm{e}}\right.$ and $\left.\mathrm{EI}_{30}\right)$ did not explain the event scaling exponent for $C_{\mathrm{e}}$ and $\mathrm{SL}_{\mathrm{e}}$ (Table 4), but $b_{1}$ of $Q_{\mathrm{e}}$ increased, i.e., it became less negative, with an increase in both $P_{\mathrm{e}}$ and $\mathrm{EI}_{30}$ (Fig. 3). Therefore, scale effects for runoff were less evident when heavy rainfall occurred. This last result appeared physically sound since it suggested that heavy rain reduces the importance of other factors determining scale effects on runoff, more related to the plot conditions at the beginning of the event (Chen et al., 2016). This conclusion is evidently approximate in this investigation because the significance of the curves of Fig. 3 was due to a single data point that could be perceived as an outlier. However, there was not any reason to exclude this particular data point from the analysis.

A clear seasonality of the scale effects was not detectable for either $Q_{\mathrm{e}}$ or $C_{\mathrm{e}}$ (Fig. 4). With reference to the former variable, both the occurrence and absence of scale effects were detectable in each month from September to February. No scale effects were detected in March and April, but only two events occurred in these 2 mo. For $C_{\mathrm{e}}$, both the occurrence and absence of scale effects were detected in some months (February, September, and October) and there was also an alternation between months with scale effects
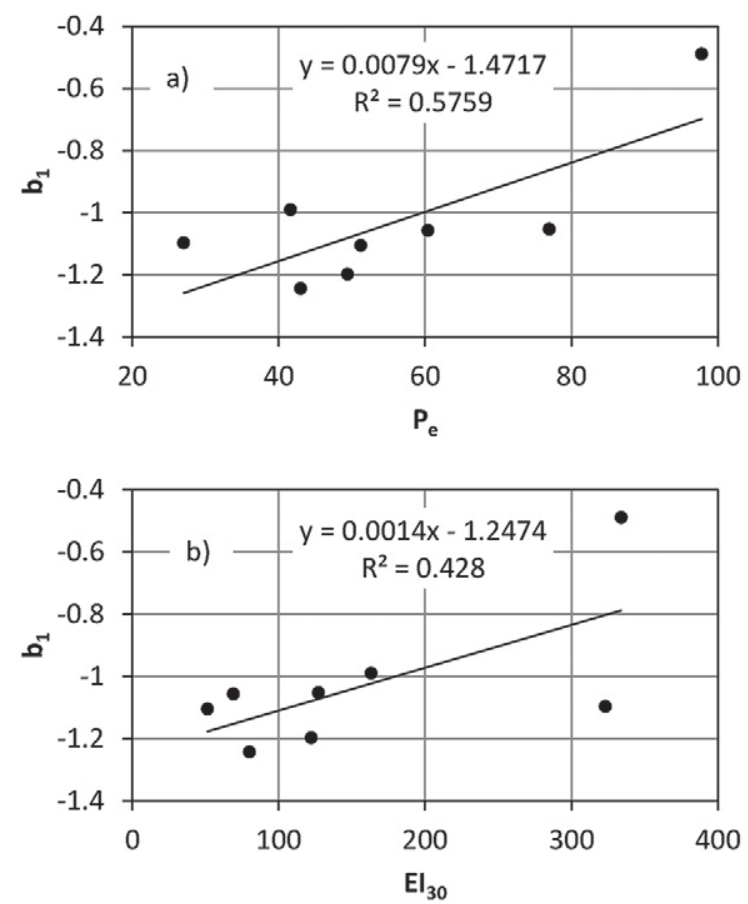

Fig. 3. Relationship between the scaling exponent $b_{1}$ of Eq. [16] and the (a) event rainfall depth, $P_{\mathrm{e}}(\mathrm{mm})$, and $(\mathrm{b})$ single-storm erosion index, $\mathrm{EI}_{30}\left(\mathrm{MJ} \mathrm{mm} \mathrm{ha} \mathrm{m}^{-1} \mathrm{~h}^{-1}\right)$, for those events suggesting a statistically significant scale effect for runoff according to Scenario 1, i.e., individual plot values against plot length (sample size $N=8$ ).
(December) and months without these effects (November and January). Some seasonality was perceivable with reference to $\mathrm{SL}_{\mathrm{e}}$. In this case, scale effects occurred in early fall and, with winter approaching, there was the possibility of not detecting these effects that disappeared completely in winter and early spring.

Using a reduced data set (17 erosive events) did not appreciably alter the mean, median, and CV values of the statistically significant scaling exponents for $Q_{\mathrm{e}}, C_{\mathrm{e}}$, and $\mathrm{SL}_{\mathrm{e}}$ (Table 5) compared with the complete data set $(N=21$, Table 4), probably because the two data sets differed by only a few events. Regardless of the considered variable, the two types of response, i.e., significant or nonsignificant scale effect, were not a consequence of differences
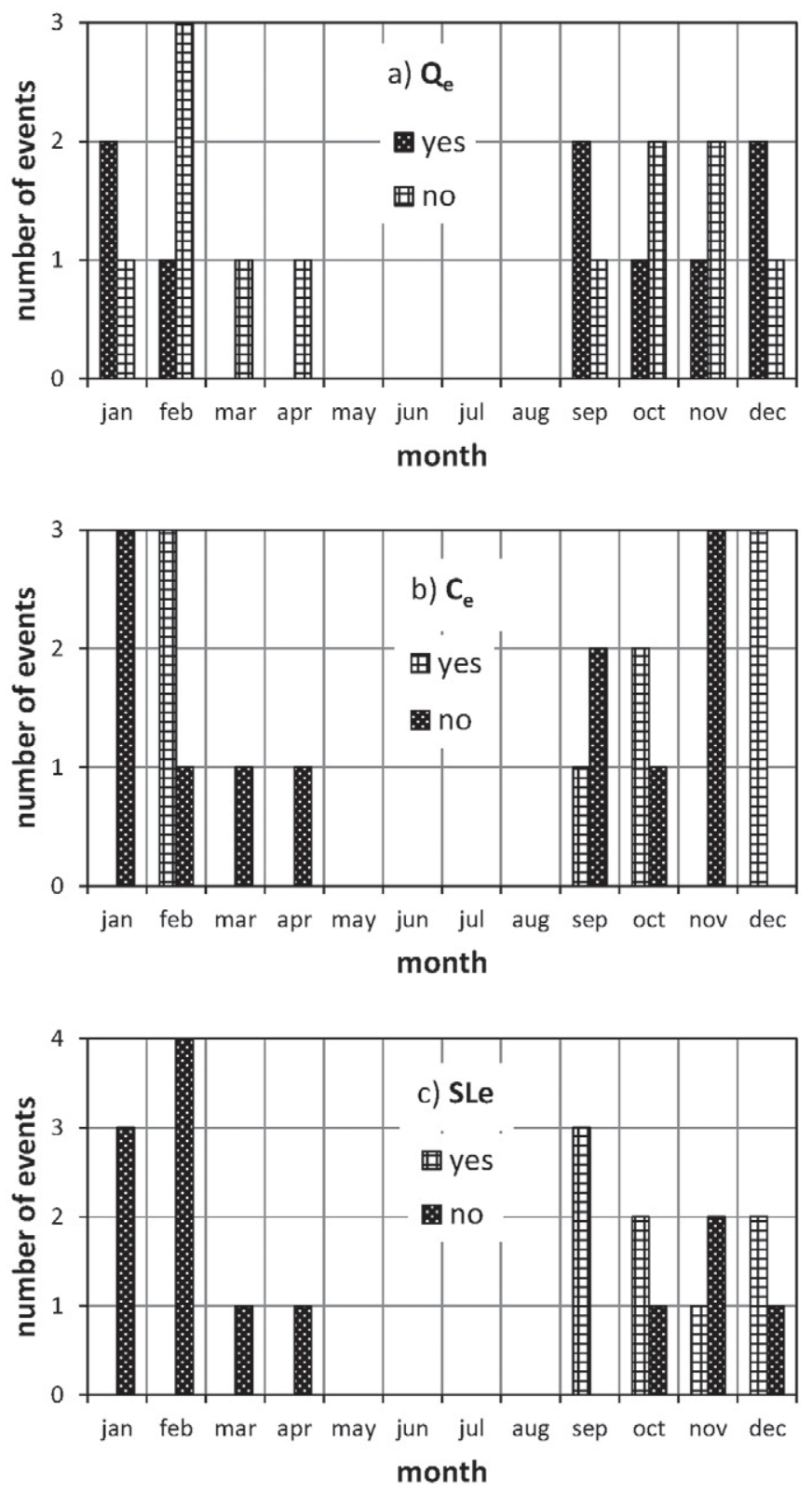

Fig. 4. Number of events with significant (yes) and nonsignificant (no) scale effects in each month of the year for (a) runoff, $Q_{\mathrm{e}}$, (b) sediment concentration, $C_{\mathrm{e}}$, and (c) soil loss per unit area, $\mathrm{SL}_{\mathrm{e}}(N=21$ events). 
Table 5. Summary statistics of the $b_{1}$ exponent of Eq. [16] for the events suggesting a significant correlation between the hydrological variable (event runoff $Q_{e}$, sediment concentration $C_{\mathrm{e}}$, and soil loss per unit area $\mathrm{SL}_{\mathrm{e}}$ ) measured on each individual plot and plot length (i.e., Scenario 1$)$, comparison between mean rainfall intensity $\left(I_{\text {med }}\right)$, maximum rainfall intensity $\left(I_{\max }\right)$, highest rainfall amount falling without interruption $\left(h_{\max }\right)$ and intensity of $h_{\max }\left(I_{h \max }\right)$, for the two groups of events (events with a significant correlation and events with a nonsignificant correlation), and results of the linear regression analysis of $b_{1}$ vs. $I_{\text {med }}, I_{\max }, h_{\max }$, and $I_{b \max }$ for those events suggesting the existence of a statistically significant scale effect (reduced data set, sample size $N=17$ events).

\begin{tabular}{|c|c|c|c|c|c|}
\hline $\begin{array}{l}\text { Variable or tested } \\
\text { relationship }\end{array}$ & Note & Statistic & $Q_{\mathrm{e}}$ & $C_{\mathrm{e}}$ & $S_{L_{e}}$ \\
\hline \multirow[t]{6}{*}{$b_{1}$} & \multirow{6}{*}{$\begin{array}{l}\text { events with a significant } \\
\text { correlation }\end{array}$} & $N$ & 6 & 8 & 8 \\
\hline & & $\min$. & -1.20 & -1.30 & -2.26 \\
\hline & & $\max$. & -0.49 & 1.73 & 1.24 \\
\hline & & mean & -0.98 & 0.58 & -0.71 \\
\hline & & median & -1.06 & 0.69 & -0.77 \\
\hline & & $\mathrm{CV}, \%$ & 25.5 & 155.8 & 174.3 \\
\hline \multirow{8}{*}{$I_{\text {med }}, \mathrm{mm} \mathrm{h}^{-1}$} & \multirow{4}{*}{$\begin{array}{l}\text { events with a significant } \\
\text { correlation }\end{array}$} & $\min$ & 12.0 & 12.1 & 12.0 \\
\hline & & $\max$. & 45.0 & 28.7 & 45.0 \\
\hline & & mean & $18.4 \mathrm{a} \dagger$ & $17.4 \mathrm{a}$ & $22.7 \mathrm{a}$ \\
\hline & & $\mathrm{CV}, \%$ & 71.4 & 39.7 & 56.2 \\
\hline & \multirow{4}{*}{$\begin{array}{l}\text { events with a } \\
\text { nonsignificant } \\
\text { correlation }\end{array}$} & $\min$. & 12.0 & 12.0 & 12.0 \\
\hline & & $\max$. & 37.2 & 45.0 & 27.9 \\
\hline & & mean & $18.9 \mathrm{a}$ & $19.8 \mathrm{a}$ & $15.2 \mathrm{a}$ \\
\hline & & $\mathrm{CV}, \%$ & 45.1 & 62.5 & 33.8 \\
\hline$b_{1}$ vs. $I_{\text {med }}$ & $\begin{array}{l}\text { events with a significant } \\
\text { correlation }\end{array}$ & $R^{2}$ & $0.0445 \mathrm{~ns} \neq$ & $0.0208 \mathrm{~ns}$ & $0.1602 \mathrm{~ns}$ \\
\hline \multirow{8}{*}{$I_{\max }, \mathrm{mm} \mathrm{h}^{-1}$} & \multirow{4}{*}{$\begin{array}{l}\text { events with a significant } \\
\text { correlation }\end{array}$} & $\min$. & 12.0 & 24.0 & 12.0 \\
\hline & & $\max$. & 156.0 & 120.0 & 156.0 \\
\hline & & mean & $60.0 \mathrm{a}$ & $63.0 \mathrm{a}$ & $75.0 \mathrm{a}$ \\
\hline & & $\mathrm{CV}, \%$ & 93.0 & 52.7 & 62.1 \\
\hline & \multirow{4}{*}{$\begin{array}{l}\text { events with a } \\
\text { nonsignificant } \\
\text { correlation }\end{array}$} & $\min$. & 12.0 & 12.0 & 12.0 \\
\hline & & $\max$. & 120.0 & 156.0 & 120.0 \\
\hline & & mean & $66.5 \mathrm{a}$ & $65.3 \mathrm{a}$ & $54.7 \mathrm{a}$ \\
\hline & & $\mathrm{CV}, \%$ & 50.6 & 75.2 & 65.0 \\
\hline$b_{1}$ vs. $I_{\max }$ & $\begin{array}{l}\text { events with a significant } \\
\text { correlation }\end{array}$ & $R^{2}$ & $0.0005 \mathrm{~ns}$ & $0.0072 \mathrm{~ns}$ & $0.0731 \mathrm{~ns}$ \\
\hline \multirow[t]{8}{*}{$h_{\max }, \mathrm{mm}$} & \multirow{4}{*}{$\begin{array}{l}\text { events with a significant } \\
\text { correlation }\end{array}$} & $\min$. & 1.0 & 1.0 & 1.6 \\
\hline & & $\max$. & 21.8 & 12.4 & 21.8 \\
\hline & & mean & 7.1a & $6.3 \mathrm{a}$ & $9.0 \mathrm{a}$ \\
\hline & & $\mathrm{CV}, \%$ & 107.9 & 63.3 & 72.6 \\
\hline & \multirow{4}{*}{$\begin{array}{l}\text { events with a } \\
\text { nonsignificant } \\
\text { correlation }\end{array}$} & $\min$. & 0.4 & 0.4 & 0.4 \\
\hline & & $\max$. & 15.2 & 21.8 & 12.4 \\
\hline & & mean & $6.6 a$ & $7.2 \mathrm{a}$ & $4.9 \mathrm{a}$ \\
\hline & & $\mathrm{CV}, \%$ & 68.4 & 96.0 & 84.0 \\
\hline$b_{1}$ vs. $h_{\max }$ & $\begin{array}{l}\text { events with a significant } \\
\text { correlation }\end{array}$ & $R^{2}$ & $0.0057 \mathrm{~ns}$ & $0.0031 \mathrm{~ns}$ & $0.2054 \mathrm{~ns}$ \\
\hline \multirow{8}{*}{$I_{h \max }, \mathrm{mm} \mathrm{h}^{-1}$} & \multirow{4}{*}{$\begin{array}{l}\text { events with a significant } \\
\text { correlation }\end{array}$} & $\min$. & 12.0 & 12.0 & 12.0 \\
\hline & & $\max$. & 118.9 & 52.0 & 118.9 \\
\hline & & mean & $37.0 \mathrm{a}$ & $27.9 \mathrm{a}$ & $40.4 \mathrm{a}$ \\
\hline & & $\mathrm{CV}, \%$ & 110.5 & 44.0 & 86.7 \\
\hline & \multirow{4}{*}{$\begin{array}{l}\text { events with a } \\
\text { nonsignificant } \\
\text { correlation }\end{array}$} & $\min$. & 12.0 & 12.0 & 12.0 \\
\hline & & $\max$. & 52.0 & 118.9 & 37.5 \\
\hline & & mean & $28.2 \mathrm{a}$ & $34.3 \mathrm{a}$ & $23.2 \mathrm{a}$ \\
\hline & & $\mathrm{CV}, \%$ & 49.2 & 99.7 & 41.8 \\
\hline$b_{1}$ vs. $I_{b \max }$ & $\begin{array}{l}\text { events with a significant } \\
\text { correlation }\end{array}$ & $R^{2}$ & $0.0116 \mathrm{~ns}$ & $0.2109 \mathrm{~ns}$ & $0.0405 \mathrm{~ns}$ \\
\hline
\end{tabular}

† For a given variable $\left(Q_{\mathrm{e}}, C_{\mathrm{e}}, \mathrm{SL}_{\mathrm{e}}\right)$, the mean values of a rainfall characteristic $\left(I_{\text {med }}, I_{\max }, h_{\max }\right.$, and $\left.I_{h \max }\right)$ followed by the same lowercase letter are not significantly different according to a two-tailed $t$-test $(P=0.05)$.

$\ddagger$ ns, coefficient of correlation not significantly $>0$ according to a one-tailed $t$-test $(P=0.05)$. in mean rainfall intensity, $I_{\text {med }}$, maximum rainfall intensity, $I_{\max }$, highest rainfall amount falling without interruption, $h_{\max }$, or the intensity of $h_{\max }, I_{h \max }$, since significant differences between the calculated $I_{\text {med }}$, $I_{\max }, h_{\max }$, and $I_{h \max }$ values for the two groups of data were never detected (Table 5). Moreover, there were no cases in which the scaling exponent was significantly correlated with the considered rainfall characteristics. Therefore, rainfall data were consistently unusable to discriminate between significant and nonsignificant scale effect situations. Moreover, they were inappropriate to explain changes in the event scaling exponent.

\section{Testing Scale Effects by Frequency Analysis of Soil Loss}

In this investigation, the way in which data from a treatment (plot length or area) were summarized (mean or median) was found to influence the detection of general trends in scale effects (Fig. 1). Therefore, an alternative approach was developed for testing scale effects with reference to the whole of the sampled events. In particular, a statistical check was performed establishing if the probability distribution of the soil loss, $\mathrm{SL}_{\mathrm{e}}$, for a given plot length was able to reproduce the empirical frequency distribution of the measured soil loss values corresponding to a different $l$ value.

Figure 5 shows the comparison between the probability distribution of the soil loss values generated by the described procedure for $l=11 \mathrm{~m}$ and the empirical cumulative frequency distribution of the measured values for $l=44 \mathrm{~m}$. This figure shows that the probability distribution of the soil loss generated for the case $l=11 \mathrm{~m}$ is not able to reproduce the cumulative distribution function of the measured values for the case $l$ $=44 \mathrm{~m}$. Furthermore, Fig. 6 shows that the probability distribution of the soil loss generated for the case $l=44$ $\mathrm{m}$ is not able to reproduce the cumulative distribution function of the measured values for the case $l=11 \mathrm{~m}$. In conclusion, the discrepancy between the probability distribution for a given plot length and the empirical distribution for another plot length indicates that a scale effect can be detected by the frequency distribution of the soil loss measured for different plot length values.

\section{Discussion}

There was a similarity between this investigation and the re-analysis of the data of Parsons et al. (2006) performed by Kinnell (2008) According to Kinnell (2008), sediment yield per unit area [M $\mathrm{L}^{-2}$ ] decreased as plot length, $l$, increased due to the decrease of the runoff volume per unit area $\left[\mathrm{L}^{3} \mathrm{~L}^{-2}\right]$ 


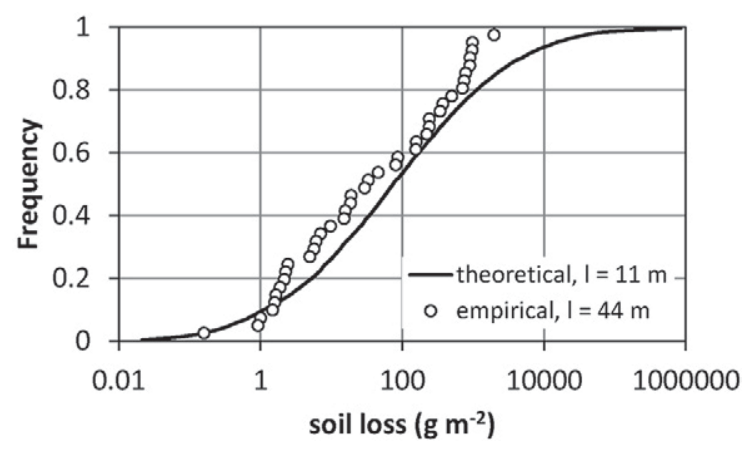

Fig. 5. Comparison between the probability distribution of the soil loss values generated for a plot length $l=11 \mathrm{~m}$ and the empirical cumulative frequency distribution of the measured values corresponding to $l=44 \mathrm{~m}$.

since sediment concentration $\left[\mathrm{M} \mathrm{L}^{-3}\right]$ was unaffected by $l$. This was also the most common condition for an inverse relationship between $\mathrm{SL}_{\mathrm{e}}$ and $l$ at Sparacia. Therefore, the runoff volume per unit area changed with plot length, but this circumstance did not have a detectable effect on the mass of sediments transported by a given runoff volume. This result appeared explainable in terms of contributing area (Rejman et al., 1999; Kidron, 2011). According to these researchers, the area that contributes to the measured sediment amount (total mass) at the base of the plot does not coincide with the entire plot area but is confined to a belt at the bottom of the slope. Therefore, the reasoning could be that $C_{\mathrm{e}}$ did not vary with $l$ because a similar area contributed to the measured total sediment amount, regardless of the plot length. The invariability of $C_{\mathrm{e}}$ with slope length (Fig. 1) suggested that an $l$ value of $11 \mathrm{~m}$ was sufficient to obtain the maximum concentration of sediments transported by flow. Therefore, a contributing area having a length of $11 \mathrm{~m}$ allowed a sediment concentration to be achieved corresponding to an equilibrium condition, close to flow transport capacity, which persisted for longer plots (22-44 m). In these longer plots, sediments were supplied from a contributing area that was not longer than $11 \mathrm{~m}$ and was localized at the downslope end of the plot.

A lower $Q_{\mathrm{e}}$ was obtained on longer plots because the total runoff volume was averaged across the entire plot area. This area included a non-contributing and a contributing part. The latter part was nearly constant among plots but the former one had an increasing weight in the calculation of $Q_{\mathrm{e}}$ for longer plots. To partially support this interpretation, the five events signaling a decreasing effect of $l$ on $Q_{\mathrm{e}}$ and a sediment concentration that was not related to $l$ (Table 3 ) were analyzed in more detail. For these events, the relationship between the cumulative runoff volume per unit plot width $\left(\mathrm{m}^{3} \mathrm{~m}^{-1}\right)$ and the plot length was investigated. The $R^{2}$ values ranged from 0.012 to 0.125 , depending on the event, and $R$ was never significantly greater than zero. The fact that, for a given plot width, the total runoff volume did not vary significantly with $l$ could be viewed as a confirmation that the plot contributing area remained nearly constant, regardless of the plot length.

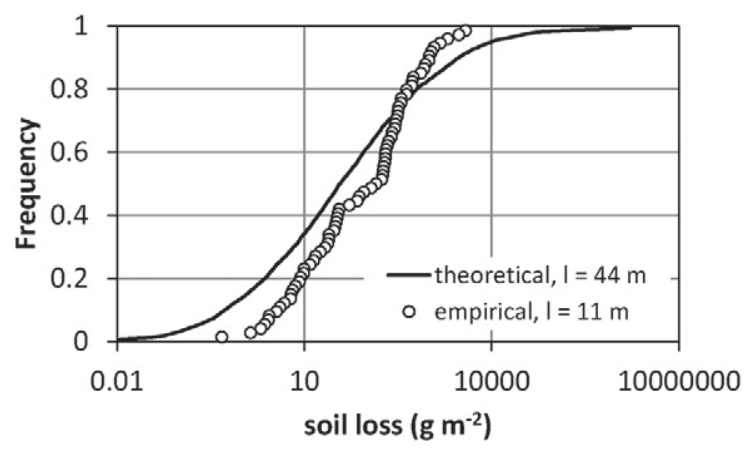

Fig. 6. Comparison between the probability distribution of the soil loss values generated for a plot length $l=44 \mathrm{~m}$ and the empirical cumulative frequency distribution of the measured values corresponding to $l=11 \mathrm{~m}$.

An implication of a contributing area that does not coincide with the entire plot area is that the conventional way for runoff and sediment yield presentation as volume or mass per unit area leads to theoretical misconceptions because only a limited portion of the plot actually participates in runoff and sediment production (Parsons et al., 2006; Kidron, 2011). However, as noted above, this kind of presentation of soil erosion data is common, especially in soil erosion models. For example, plot soil loss is presented as mass per unit area in the USLE and USLE-type models, including the USLE-M and the USLE-MM that was originally developed at Sparacia (Wischmeier and Smith, 1978; Renard et al., 1997; Kinnell and Risse, 1998; Bagarello et al., 2010). In these last two models, the erosivity term is given by the product between the runoff coefficient, $Q_{\mathrm{R}}$, and the single-storm erosion index of the USLE, $\mathrm{EI}_{30}$. In a recent investigation by Bagarello et al. (2015), the specific function for the plot length topographic factor of the USLE-MM confirmed that soil loss per unit area should increase with $l$ and it did not differ appreciably from other, more accepted, relationships (e.g., Renard et al., 1997). The fact that $\mathrm{SL}_{\mathrm{e}}$ decreased or did not vary with $l$ in this investigation could be viewed as a reason for perplexity in the robustness in the developed analyses, also taking into account that most of the data used here (i.e., excluding the most recent ones) were also included in the database of Bagarello et al. (2015). The current version of the USLE-MM makes use of the measured runoff coefficient because $Q_{\mathrm{R}}$ estimating procedures have still not been tested or developed. This is a practical limitation to the use of the model. However, this necessity has the advantage that the hydrological response of the plot is directly taken into account for predicting soil loss. In other terms, an erosivity term including a scale-dependent runoff coefficient appears appropriate to predict soil loss per unit area that does not necessarily increase with the plot length.

In this investigation, a power law relationship was considered to check scale effects because it is theoretically based and it represents a rather diffused approach (e.g., Bagarello and Ferro, 2010; Xu et al., 2009; Moreno-de las Heras et al., 2010). Another reason was that Chen et al. (2016) demonstrated its usability with numerically 
simulated data and they also suggested to consider the exponent of Eq. [16] as a measure of the scale effect. However, other relationships (e.g., linear or polynomial) have also been used to check scale effects (e.g., Lal, 1997; Kinnell, 2008). The data do not always yield a clear indication of the scale relationship that should be used. As an example, Fig. 7 shows, for the event of 13 Oct. 2004 at Sparacia, that the scale effect for runoff could indifferently be described by a linear and a power relationship. The fitting to the data is similar for the two relationships $\left(R^{2}=0.81-0.84\right)$ but the information is very different. Moving from $l=11$ to $44 \mathrm{~m}$, runoff decreases by 4.6 and 9.1 times according to the power and the linear relationship, respectively. The scale effect appears to become insignificant beyond a certain threshold value in the former case (Chen et al., 2016) but not in the latter one. Therefore, predicted scale effects could depend on the relationship used to summarize the data. Developing this issue in future research could make data interpretation more robust in general.

Scale issues should explicitly be taken into account in the comparison between two treatments (e.g., runoff from vegetated and bare plots). For example, a comparison made at a given plot scale could be invalid for another plot scale if the scaling exponent of Eq. [16] differs greatly between the two treatments. In the absence of a specific testing of scale effects, it seems prudent to assume that a comparison made at a given scale is only valid at the tested plot scale.

\section{Conclusions}

Plot-scale effects on event runoff per unit area, $Q_{e}$, sediment concentration, $C_{\mathrm{e}}$, and soil loss per unit area, $\mathrm{SL}_{\mathrm{e}}$, were tested at the Sparacia (south Italy) experimental area using a power relationship in which the scaling exponent represents a measure of the scale effect for the considered variable within the sampled plot sizes. The application of dimensional analysis and self-similarity theory allowed recognition that the power scaling relationship can be theoretically deduced.

Similar information was obtained by considering different dependent variables, i.e., individual values for each plot or mean of the replicates, and scale indicators, i.e., plot length, $l$, or plot area, $A$. In particular, the developed analysis showed that the scaling exponent for the plot area is half of the scaling exponent for the length. Using individual values of the considered variable against plot length yielded the highest number of significant scale effects in this investigation. The theoretical assumption $A \sim l^{2}$ was experimentally supported and the relationship between the scaling exponents for $l$ and $A$ was independent of the considered hydrological or erosion variable.

The most common result was the lack of any scale effect ( $57-62 \%$ of the cases, depending on the considered variable). When these effects were detectable, they suggested a decreasing trend of $Q_{\mathrm{e}}$ with $l$. The $C_{\mathrm{e}}$ values generally (i.e., most of the time) increased with $l$ whereas



Fig. 7. Runoff, $Q_{\mathrm{e}}$, vs. plot length, $l$, for the event of 13 Oct. 2004 at the Sparacia experimental station.

$\mathrm{SL}_{\mathrm{e}}$ generally decreased. Scale effects were highly variable from one event to another with reference to the latter two variables, but they showed a reduced variability with the event for runoff.

Rainfall characteristics did not explain the occurrence or not of significant scale effects nor were they able to describe changes in the scaling exponent for $C_{\mathrm{e}}$ and $\mathrm{SL}_{\mathrm{e}}$. For $Q_{\mathrm{e}}$, scale effects on plot runoff should be expected to decrease as rainfall amount or its erosivity increase.

The hypothesis that the area that contributes to the total mass of sediments reaching the base of a plot could not coincide with the entire plot area but is confined to a narrow belt at the bottom of the slope was supported in this investigation by a runoff per unit area that decreases as plot length increases and a sediment concentration that does not vary with $l$.

Finally, a new statistical approach was proposed to check scaling effects using the probability distribution of the involved variables. This method has the advantage of using entire historical sequences instead of comparing single event values.

\section{References}

Asadzadeh, F., M. Gorji, A. Vaezi, R. Sokouti, and M. Shorafa. 2012. Scale effect on runoff from filed plots under natural rainfall. Am.-Eurasian J. Agric. Environ. Sci. 12:1148-1152. doi:10.5829/idosi.aejaes.2012.12.09.1682

Bagarello, V., G.V. Di Piazza, V. Ferro, and G. Giordano. 2008. Predicting unit plot soil loss in Sicily, south Italy. Hydrol. Processes 22:586-595. doi:10.1002/hyp.6621

Bagarello, V., and V. Ferro. 2004. Plot-scale measurement of soil erosion at the experimental area of Sparacia (southern Italy). Hydrol. Processes 18:141-157. doi:10.1002/hyp.1318

Bagarello, V., and V. Ferro. 2010. Analysis of soil loss data from plots of differing length for the Sparacia experimental area, Sicily, Italy. Biosyst. Eng. 105:41 1-422. doi:10.1016/j.biosystemseng.2009.12.015

Bagarello, V., and V. Ferro. 2017. Supporting USLE-MM reliability by analyzing soil loss measurement errors. Hydrol. Processes 31:847-853. doi:10.1002/hyp. 11063

Bagarello, V., V. Ferro, and G. Giordano. 2010. Testing alternative erosivity indices to predict event soil loss from bare plots in southern Italy. Hydrol. Processes 24:789-797. doi:10.1002/hyp.7538

Bagarello, V., V. Ferro, G. Giordano, F. Mannocchi, V. Pampalone, F. Todisco, and L. Vergni. 2011. Effect of plot size on measured soil loss for two Italian experimental sites. Biosyst. Eng. 108:18-27. doi:10.1016/j.biosystemseng.2010.10.006 
Bagarello, V., V. Ferro, and V. Pampalone. 2015. A new version of the USLEMM for predicting bare plot soil loss at the Sparacia (South Italy) experimental site. Hydrol. Processes 29:4210-4219. doi:10.1002/hyp.10486

Barenblatt, G.I. 1979. Scaling, self-similarity, and intermediate asymptotics. Cambridge Univ. Press, Cambridge, UK.

Barenblatt, G.I. 1987. Dimensional analysis. Gordon \& Breach Sci. Publ. Amsterdam.

Cerdan, O., Y. Le Bissonnais, G. Govers, V. Lecomte, K. Van Oost, A. Cou turier, et al. 2004. Scale effect on runoff from experimental plots to catchments in agricultural areas in Normandy. J. Hydrol. 299:4-14. doi:10.1016/j.jhydrol.2004.02.017

Chaplot, V., and Y. Le Bissonnais. 2000. Field measurement of interrill erosion under different slopes and plot sizes. Earth Surf. Processes Landforms 25:145-153. doi:10.1002/(SICI) 1096-9837(200002)25:2<145::AIDESP51>3.0.CO;2-3

Chen, L., S. Sela, T. Svoray, and S. Assouline. 2016. Scale dependence of Hortonian rainfall-runoff processes in a semiarid environment. Water Resour. Res. 52:5149-5166. doi:10.1002/2015WR018315

Di Stefano, C., and V. Ferro. 2016. Establishing soil loss tolerance: An overview. J. Agric. Eng. 47:127-133. doi:10.4081/jae.2016.560

Joel, A., I. Messing, O. Seguel, and M. Casanova. 2002. Measurement of surface water runoff from plots of two different sizes. Hydrol. Processes 16:1467-1478. doi:10.1002/hyp.356

Kidron, G.J. 2011. Runoff generation and sediment yield on homogeneous dune slopes: Scale effect and implications for analysis. Earth Surf. Processes Landforms 36:1809-1824. doi:10.1002/esp.2203

Kinnell, P.I.A. 2008. Comment on "Scale relationships in hillslope runoff and erosion" (Earth Surface Processes and Landforms 31:1364-1383 (2006)). Earth Surf. Processes Landforms 33:1632-1636. doi:10.1002/esp.1630

Kinnell, P.I.A., and L.M. Risse. 1998. USLE-M: Empirical modeling rainfall erosion through runoff and sediment concentration. Soil Sci. Soc. Am. J. 62:1667-1672. doi:10.2136/sssaj1998.03615995006200060026x

Lal, R. 1997. Soil degradative effects of slope length and tillage methods on Alfisols in western Nigeria: I. Runoff, erosion and crop response. Land Degrad. Dev. 8:201-219. doi:10.1002/(SICI)1099 145X(199709)8:3<201::AID-LDR253>3.0.CO;2-U

Loch, R.J. 1996. Using rill/interrill comparisons to infer likely responses of erosion to slope length: Implications for land management. Aust. J. Soil Res. 34:489-502. doi:10.1071/SR9960489

Moreno-de las Heras, M. J.M. Nicolau, L. Merino-Martín, and B.P. Wilcox. 2010. Plot-scale effects on runoff and erosion along a slope degradation gradient. Water Resour. Res. 46:W04503.

Nearing, M.A. 1998. Why soil erosion models over-predict small soil losses and under-predict large soil losses. Catena 32:15-22.
doi:10.1016/S0341-8162(97)00052-0

Nearing, M.A. 2000. Evaluating soil erosion models using measured plo data: Accounting for variability in the data. Earth Surf. Processes Landforms 25:1035-1043. doi:10.1002/1096-9837(200008)25:9<1035::AIDESP121>3.0.CO;2-B

Parsons, A.J., R.E. Brazier, J. Wainwright, and D.M. Powell. 2006. Scale relationships in hillslope runoff and erosion. Earth Surf. Processes Landforms 31:1384-1393. doi:10.1002/esp.1345

Parsons, A.J., R.E. Brazier, J. Wainwright, and D.M. Powell. 2008. Scale relationships in hillslope runoff and erosion: Reply. Earth Surf. Processes Landforms 33:1637-1638. doi:10.1002/esp.1628

Rejman, J., and R. Brodowski. 2005. Rill characteristics and sediment transport as a function of slope length during a storm event on loess soil. Earth Surf. Processes Landforms 30:231-239. doi:10.1002/esp.1177

Rejman, J., and B. Usowicz. 2002. Evaluation of soil-loss contribution areas on loess soils in southeast Poland. Earth Surf. Processes Landforms 27:1415-1423. doi:10.1002/esp.438

Rejman, J., B. Usowicz, and R. Dębicki. 1999. Source of errors in predicting silt soil erodibility with USLE. Pol. J. Soil Sci. 32(1):13-22.

Renard, K.G., G.R. Foster, G.A. Weesies, D.K. McCool, and D.C. Yoder. 1997. Predicting soil erosion by water: A guide to conservation planning with the Revised Universal Soil Loss Equation (RUSLE). Agric. Handb.703. US Gov. Print. Office, Washington, DC.

Sadeghi, S.H.R., M.B. Seghaleh, and A.S. Rangavar. 2013. Plot sizes dependency of runoff and sediment yield estimates from a small watershed. Catena 102:55-61. doi:10.1016/j.catena.2011.01.003

Spiegel, M.R. 1961. Theory and problems of statistics. McGraw-Hill, New York

Thomaz, E.L., and L.R. Vestena. 2012. Measurement of runoff and soil loss from two differently sized plots in a subtropical environment (Brazil). Earth Surf. Processes Landforms 37:363-373. doi:10.1002/esp.2242

Wendt, R.C., E.E. Alberts, and A.T. Hjelmfelt, Jr.. 1986. Variability of runoff and soil loss from fallow experimental plots. Soil Sci. Soc. Am. J. 50:730736. doi:10.2136/sssaj1986.03615995005000030035x

Wischmeier, W.H., and D.D. Smith. 1978. Predicting rainfall erosion losses: A guide to conservation planning. Agric. Handb. 537. US Gov. Print. Office, Washington, DC

Xu, X.-L., W. Liu, Y.-P. Kong, K.-L. Zhang, B. Yu, and J.-D. Chen. 2009 Runoff and water erosion on road side-slopes: Effects of rainfall characteristics and slope length. Transp. Res. D 14:497-501. doi:10.1016/j.trd.2009.05.006

Yair, A., and N. Raz-Yassif. 2004. Hydrological processes in a small arid catchment: Scale effects of rainfall and slope length. Geomorphology 61:155-169. doi:10.1016/j.geomorph.2003.12.003 